\title{
Poly(ethylene-co-butylene) functionalized multi walled carbon nanotubes applied in polypropylene nanocomposites
}

Daugaard, Anders Egede; Jankova Atanasova, Katja ; Marín, Jose Manuel Roman; Bøgelund, Jesper; Hvilsted, Søren

\author{
Published in: \\ European Polymer Journal
}

Link to article, DOI:

10.1016/j.eurpolymj.2012.02.006

Publication date:

2012

Link back to DTU Orbit

Citation $(A P A)$ :

Daugaard, A. E., Jankova Atanasova, K., Marín, J. M. R., Bøgelund, J., \& Hvilsted, S. (2012). Poly(ethylene-cobutylene) functionalized multi walled carbon nanotubes applied in polypropylene nanocomposites. European Polymer Journal, 48(4), 743-750. https://doi.org/10.1016/j.eurpolymj.2012.02.006

\section{General rights}

Copyright and moral rights for the publications made accessible in the public portal are retained by the authors and/or other copyright owners and it is a condition of accessing publications that users recognise and abide by the legal requirements associated with these rights.

- Users may download and print one copy of any publication from the public portal for the purpose of private study or research.

- You may not further distribute the material or use it for any profit-making activity or commercial gain

- You may freely distribute the URL identifying the publication in the public portal 


\section{Poly(ethylene-co-butylene) Functionalized Multi Walled Carbon Nanotubes Applied in Polypropylene Nanocomposites}

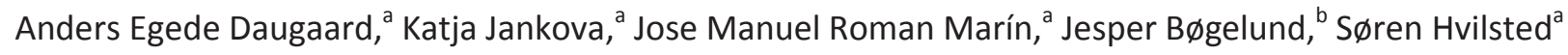

${ }^{a}$ Danish Polymer Centre, Department of Chemical and Biochemical Engineering, Technical University of Denmark, Søltofts Plads, Building 229, DK-2800 Kgs. Lyngby, Denmark (adt@kt.dtu.dk).

${ }^{b}$ Danish Technological Institute, Taastrup, Gregersensvej 3, DK-2630 Taastrup, Denmark.

\section{Abstract}

A novel functionalized multi walled carbon nanotube (MWCNT) was prepared through grafting with $\alpha$ azido-poly(ethylene-co-butylene) (PEB-N $\mathrm{N}_{3}$ ). The PEB- $\mathrm{N}_{3}$ was prepared through a two step procedure and grafted onto an industrial grade multi walled carbon nanotube (MWCNT) through a highly efficient nitrene addition. This novel nano filler was melt mixed into polypropylene (PP) and the composite was characterized by FT-IR spectroscopy, Raman spectroscopy, Scanning Electron Microscopy (SEM), Rheology and Dielectric relaxation spectroscopy (DRS). The analyses showed that composites with the novel filler had a high degree of discharge from the surface and higher conductivity compared to the pristine filler, illustrating an efficient conductive network in the composites. The composites showed low percolation thresholds of $0.3 \mathrm{wt} \%(0.15 \mathrm{vol} \%)$ as well as improved stability at a range of temperatures from $25-135^{\circ} \mathrm{C}$.

Keywords: Polymer Synthesis; Polymer Compatibilisation; Nitrene addition; Multi Walled Carbon Nanotubes; Composites; Dielectric Relaxation Spectroscopy

\section{Introductions}

A large number of nanocomposites employing different nanofillers have emerged during the last decade, where especially nanoclay and carbon nanotubes (CNT) have been ascribed great potential (1). The mechanical as well as the electrical properties that could be obtained through exploitation of CNTs have inspired much work on materials $(2,3)$. In particular the conductive properties of CNT fillers have led to a number of applications in electrics (4) such as in electrostatic charge dissipation (ESC) (5), electromagnetic interference screening (EMI) $(6,7)$ or as bipolar plates in fuel cells (8). For electric applications the low percolation thresholds generally observed for CNT fillers (9) enable lower loading of fillers compared to alternatives such as carbon black or graphite. In addition to this, CNT also contribute to the mechanical properties through strengthening of the composite, which enables a number of novel applications. With the cost of CNT decreasing rapidly application of these materials as fillers in commodity plastics such as polypropylene (PP) has become increasingly attractive.

The most common method for dispersion of CNTs in PP has been melt mixing for prolonged periods of time. As an alternative to long mixing times, where the aspect ratio of the CNT can be reduced drastically through degradation, functionalization of CNTs is known to facilitate dispersion of fillers in polymer 
composites (10). This approach has been proven to give mechanical improvements of PP composites, where e.g. amine functional MWCNT has been reacted with maleated PP(11) or butyl lithium has been used to activate the MWCNT surface and applied in subsequent grafting with chlorinated PP(12). However, for electronic properties the functionalization approach has generally been found to result in a decrease of the conductivity of the CNT due to disruption of conjugation $(13,14)$. This result is heavily influenced by the method of functionalization as well as the extent of functionalization, and Lee et al.(15) has shown that a heat treatment or modification with low molecular weight compounds of the MWCNT could be applied to obtain an increased conductivity of a PP MWCNT composite. Often oxidative methods are involved in the purification or applied to introduce functional groups to the CNT. Such methods are known to cause degradation and shortening the tubes, which normally results in a substantial reduction of the conductive properties. Alternatively covalent functionalization of CNTs by non-oxidative methods can be performed through in situ generation of reactive species such as radicals, carbenes and nitrenes or by cycloaddition onto CNT as described in recent reviews $(10,16)$. For polymer grafting of CNTs (17) especially radical (18$21)$ and nitrene $(22,23)$ approaches have been applied, since the reactive groups required for grafting can be introduced through common polymer endgroups. There are two examples of radical grafting of MWCNT in PP, where benzoyl peroxide has been applied in melt mixing $(24,25)$. In one case the material was used for drawing fibers and here a substantial improvement was observed(24), while in the other only moderate mechanical improvements were observed(25). In these investigations the effects upon conductivity was not addressed.

Here a new concept with nitrene grafting of an azide functional PEB-N $\mathrm{N}_{3}$ onto a MWCNT was exploited to obtain a novel functional nano filler for PP. PEB is a well known compatibilizer for polyolefines, and this is to our knowledge the first application of it for functionalization of MWCNT. A low loading of PEB was targeted in order to preserve the conjugation of the system, while still striving for a compatibilizing effect to obtain a composite suitable for electronic applications.

\section{Experimental}

\section{General methods and materials}

MWCNTs with an average diameter of $9.5 \mathrm{~nm}$ and average length of $1.5 \mu \mathrm{m}$ were purchased from Nanocyl S. A. (Belgium) and were used as received. Isotactic polypropylene was acquired from Lyondellbasell (HM562S, melt flow rate 30g/10min). Poly(ethylene-co-butylene)-OH (PEB-OH, $M_{n}=7000 \mathrm{~g} / \mathrm{mol}$, Kraton Liquid Polymer L-1203) was donated by Kuraray Co., Ltd. (Japan), all other chemicals were acquired from Sigma-Aldrich and used as received.

Nuclear magnetic resonance (NMR) spectroscopy was performed on a $300 \mathrm{MHz}$ Cryomagnet from Spectrospin \& Bruker, at room temperature. Infrared spectroscopy (ATR-FTIR) was performed on a PerkinElmer Spectrum One model 2000 Fourier Transform Infrared system with a universal Attenuated Total Reflection sampling accessory on a ZnSe/diamond composite. Differential Scanning Calorimetry (DSC) was performed on a DSC Q1000 DSC from TA Instruments. The thermal analysis was performed at a heating and cooling rate of $10{ }^{\circ} \mathrm{C} / \mathrm{min}$. The glass transition temperatures $\left(T_{g}\right.$ 's) were measured at the inflection point. Thermo gravimetric analysis (TGA) was performed in a nitrogen atmosphere on a Q500 from TA instuments with a heating rate of $10{ }^{\circ} \mathrm{C} / \mathrm{min}$ from RT to $800{ }^{\circ} \mathrm{C}$. Size Exclusion Chromatography (SEC) 
analyses were performed in THF on two Polymer Laboratories PLgel $5-\mu \mathrm{m}$ Mixed-D columns ( $300 \times 7.5 \mathrm{~mm}$ ) with a Shimadzu SIL-10AD auto injector, a Shimadzu LC10AD pump and a Viscotek 200 difractometer detector. The number-average molecular weight $\left(\mathrm{M}_{n}\right)$ and polydispersity index (PDI) values were determined with polystyrene standards. Scanning electron microscopy (SEM) was performed on a Quanta 200F from FEI Instruments. Ultra sonication was performed with a Hielscher UP200S. Extrudates were prepared on a Haake mini lab extruder (7 min @ 50 RPM). Raman spectra were recorded on a Thermo DXR dispersive Raman microscope with a $780 \mathrm{~nm}$ laser. Small amplitude oscillatory shear measurements were made on an AR2000 rheometer from TA Instruments using parallel plate geometry with a diameter of 25 $\mathrm{mm}$ and a plate separation of $0.9 \mathrm{~mm}$. The measurements were performed at $200^{\circ} \mathrm{C}$ and frequency sweep between $0.01 \mathrm{rad} / \mathrm{s}$ and $100 \mathrm{rad} / \mathrm{s}$ were made at a low strain of 2\%. Dielectric Relaxation Spectroscopy (DRS) was performed on a Novocontrol Alpha-A high performance frequency analyzer.

\section{Preparation of PEB functionalized MWCNT}

PEB-OH (0.493 g, $\mathrm{M}_{\mathrm{n}}=7000 \mathrm{~g} / \mathrm{mol}, \mathrm{PDI}=1.04,0.07 \mathrm{mmol}$ OH group) was dissolved in distilled THF at $0{ }^{\circ} \mathrm{C}$. $\mathrm{Et}_{3} \mathrm{~N}(0.06 \mathrm{~mL}, 0.43 \mathrm{mmol}$ ) and a solution of mesyl chloride (MsCl, $0.022 \mathrm{~mL}, 0.28 \mathrm{mmol}$, in $0.2 \mathrm{~mL} \mathrm{THF}$ ) was added dropwise to the reaction mixture. The mixture was stirred under nitrogen for $18 \mathrm{~h}$ while it was allowed to reach room temperature. The mixture was filtered and precipitated into $\mathrm{MeOH}$. The solvent was decanted and the residue was dissolved in toluene and precipitated into $\mathrm{MeOH}$ again. PEB-OMs was recovered after decantation of the solvent as a clear viscous liquid $(0.42 \mathrm{~g}, 83 \%)$ and used without further purification.

PEB-OMs ( $0.400 \mathrm{~g}, 0.06 \mathrm{mmol}$ functional group) was dissolved in THF $(2.7 \mathrm{~mL})$ and azidotrimethylsilane ( $0.031 \mathrm{~mL}, 0.24 \mathrm{mmol}$ ) as well as tetrabutylammonium fluoride (TBAF, $0.235 \mathrm{~mL}, 0.24 \mathrm{mmol}$ ) was added to the mixture, which was stirred under nitrogen at room temperature for $18 \mathrm{~h}$. The crude was isolated by precipitation into $\mathrm{MeOH}$, the solution was decanted and the residue was dissolved in toluene and precipitated again into $\mathrm{MeOH}$. $\mathrm{PEB}-\mathrm{N}_{3}$ was isolated upon decantation of the $\mathrm{MeOH}$ solution and drying in vacuo as a viscous liquid (0.16 $\mathrm{g}, 39 \%)$.

IR $\left(\mathrm{cm}^{-1}\right)$ : 3100-2800 (CH stretch); 2095 ( $\mathrm{N}_{3}$ stretch). ${ }^{1} \mathrm{H}-\mathrm{NMR}(300 \mathrm{MHz}) \mathrm{CDCl}_{3}, \delta_{\mathrm{H}}(\mathrm{ppm}):$ 0.6-2.0 $(\mathrm{m}$, corresponds to polymer backbone); $3.27\left(\mathrm{t}, 2 \mathrm{H},{ }^{3} \mathrm{~J}=7.4 \mathrm{~Hz}, \mathrm{CH}_{2} \mathrm{CH}_{2} \mathrm{~N}_{3}\right)$.

The pristine MWCNT $(0.5 \mathrm{~g})$ and PEB- $\mathrm{N}_{3}(0.05 \mathrm{~g}, 0.007 \mathrm{mmol})$ were suspended in xylene at $130{ }^{\circ} \mathrm{C}$ under a nitrogen atmosphere for $20 \mathrm{~h}$. The suspension was filtered on a $0.4 \mu \mathrm{m}$ filter, rinsed with $\mathrm{CH}_{2} \mathrm{Cl}_{2}$ and dried in vacuo to obtain PEB-MWCNT as a black powder in quantitative yield. TGA shows $7.4 \mathrm{wt} \%$ of polymer on the MWCNT.

\section{Preparation of MWCNT PP master batch}

The pristine or functionalized MWCNT ( $0.5 \mathrm{~g}$ ) was dispersed in xylene by ultra sonication ( $3 \times 30 \mathrm{~s})$ and transferred into a solution of melted PP $(5 \mathrm{~g})$ in xylene at $170^{\circ} \mathrm{C}$. The melt dispersion was stirred for approximately $10 \mathrm{~min}$, and the solvent was removed by rotary evaporation to ensure that the filler remains dispersed in the polymer melt through agitation. The solid master batch was isolated after drying in vacuo over night at $50^{\circ} \mathrm{C}$. 


\section{Results and discussion}

The MWCNT was functionalized through nitrene addition, as has earlier been done with azide functional polystyrene onto single walled carbon nanotubes by Qin et al.(23). For this purpose, an azide functional poly(ethylene-co-butylene) (PEB- $\mathrm{N}_{3}$ ) was prepared through mesylation of the end group and subsequent conversion into the azide. PEB- $\mathrm{N}_{3}$ was reacted onto the MWCNT by thermolysis of the azide, resulting in nitrene addition in xylene at $130^{\circ} \mathrm{C}$ as shown in Scheme 1.

Scheme 1

The obtained functionalized MWCNT was found to contain $7.4 \mathrm{wt} \%$ of PEB by Thermo Gravimetric Analysis (TGA) as shown in Figure 1(a). The TGA results points to a high grafting efficiency since most of the employed PEB- $\mathrm{N}_{3}$ ends up grafted to the MWCNT. Compared with the grafting procedure developed by Qin et al. (23) this efficiency is high. There a large excess of PS- $\mathrm{N}_{3}$ was applied (1 g of PS- $\mathrm{N}_{3}$ to $15 \mathrm{mg}$ of SWCNT) in order to push the extent of the reaction and obtain a high loading of PS (85 wt\%) at a much lower efficiency. However, the method is well suited for obtaining moderate loading of polymer as illustrated here. The functionalization was indicated by IR spectroscopy, where a minor difference between the IR spectrum of the functionalized MWCNT relative to the pristine starting material indicates that the MWCNT has been modified (supporting information Figure 1). Raman spectroscopy shown in Figure 1(b) corroborates this.

Figure $1 \mathrm{a}$ and $\mathrm{b}$

In the Raman spectra the increase in the D-band (at $1310 \mathrm{~cm}^{-1}$, Figure $1 \mathrm{~b}$ ) signifies an increase in defects or $\mathrm{sp}^{3}$ hybridized carbons for the PEB-MWCNT compared to the pristine material. The $\mathrm{D}$ to $\mathrm{G}$ band $\left(1590 \mathrm{~cm}^{-1}\right)$ intensity ratio has been increased after functionalization from $I_{D / G}=1.48$ in the starting material to $I_{D / G}=1.83$ in the PEB-MWCNT, which confirms covalent functionalization of the MWNCT sidewall (26).

PP composites containing the modified filler were prepared on a lab scale mini extruder. To ensure a good dispersion of the nanofiller in the composite several dispersion methods were tested (e.g. direct mixing in extruder, melt mixing, solvent dispersion combined with melt mixing) (27). Oscillatory linear shear rheology was applied to evaluate the dispersion of composites prepared from the different master batches based on the height of the plateau in $\mathrm{G}^{\prime}$ (supporting information Figure 2). It was found that a combination of a dispersion/dissolution method at high temperature followed by removal of the solvents on a rotary evaporator provided the best master batches. Composites containing pristine or functionalized MWCNT were prepared through dilution of master batches by melt mixing in the mini extruder to concentrations of $1 \mathrm{wt} \%, 0.6 \mathrm{wt} \%, 0.3 \mathrm{wt} \%$ and $0.1 \mathrm{wt} \%$ MWCNT, which were subsequently pressed into discs on a hot press for further analysis.

The composites were characterized by DSC, FT-IR and Raman spectroscopy. DSC showed a minor increase in crystallization temperature with increased content of MWCNT for all composites as reported for other PP/MWCNT systems (28). Raman spectroscopy clearly confirms the presence of MWCNT in the composites, where strong resonances of the $D$ and $G$ bands at respectively 1310 and $1590 \mathrm{~cm}^{-1}$ from the MWCNT, dominate the spectra even at $0.1 \mathrm{wt} \%$ concentration, confirming the presence of the MWCNT in all the composites (supporting information Figure 3). The influence of the functionalization (and loading) upon dispersion was investigated by SEM as shown in Figure 2. 
Figure 2

The micrographs have been obtained under high voltage conditions as described by Loos(9) and Lillehei (29). This allows charges to accumulate on areas of the sample that are not part of the percolated network. Thereby it can give an indication of the extent of the percolated network for the different samples. As can be seen in Figure 2 the difference is most apparent at the highest loading (1wt\%), where there is a major difference in discharge of the composite with the functionalized filler compared to the composite with the pristine MWCNT. For samples with lower concentrations of nanotubes there appears to be a trend towards increased charging of the surface with decreased content of nanotubes. In the respective micrographs it is possible to identify single tubes underlining the presence of dispersed material in the composites. The quality of the dispersion was additionally investigated by oscillatory linear shear rheology (supporting information Figure 4), where the measurements show the characteristic non-terminal behavior of the storage modulus, $\mathrm{G}^{\prime}$, which is attributed to the formation of a carbon nanotube network in the PP matrix. This is directly related to the dispersion of CNT as described by others $(30,31)$. With an increase in the filler content an increase in the $\mathrm{G}^{\prime}$ plateau is observed for both pristine and functionalized MWCNT. This corroborates a good incorporation of the filler into the matrix where there is a substantial influence upon the rheological properties. Compared to e.g. the work presented by Lee et al.(15) the general level of dispersion is much better at a lower loading of MWCNT and a distinct plateau can be observed at all loadings, which is in contrary to the observations mentioned above(15). Interestingly, there appears to be only minor differences between composites with the functionalized and pristine filler, which is a result of the optimized master batch procedure. From SEM there appears to be a substantial difference in the electronic properties of the samples, though this apparently is not reflected in the rheological properties. This was investigated through dielectric relaxation spectroscopy (DRS), where the electronic properties of the composites were characterized as shown in Figure 3.

Figure $3 a$ and $b$

The variation in the conductivity with frequency follows a power law behavior for samples containing $0.1 \mathrm{wt} \%$ filler and for the pure PP, which is typical for insulating materials. Samples containing more than $0.3 \mathrm{wt} \%$ show a direct current plateau at lower frequencies, which is indicative for conductive materials. The onset of the plateau is significantly different for the pristine and functionalized material as summarized in Table 1. In the pristine material a plateau in conductivity is observed below a fixed frequency of $1670 \mathrm{~Hz}$, whereas for the functionalized material this critical frequency $\left(f_{c}\right)$ varies with the content of filler.

Furthermore, a conductivity threshold can be observed in the pristine samples where conductivity does not increase with increased loading. This is not the case for the PEB-MWCNT filled material, which is interesting as it indicates that there is only a limited effect of increased content of pristine tubes under melt mixing conditions compared to an increase in functionalized tubes. This corroborates that the functionalization improves the dispersion of the filler. All the conductivities observed for these samples are decades above what has been observed in PP systems for modified tubes at low loading of filler by Lee et al. (15). The measurements also indicate that the percolation threshold in both cases is below $0.3 \mathrm{wt} \%$, which corresponds to 0.15 vol\% (as shown in Table 1).

Table 1 
This percolation threshold is low compared to other PP based systems (8.4 wt\% (32) and $1.2 \mathrm{wt} \%$ (28)), though Tjong et al. (33) reported an almost similar threshold of $0.43 \mathrm{wt} \%$.

In addition to the electronic characterization, DRS also provide valuable information about polarization phenomena in polymer matrices. Especially, in the complex permittivity large differences can be observed between composites with the functional and the pristine filler as shown in Figure 4.

Figure $4 a$ and $b$

From the spectra it is clear that the pristine and the functionalized material perform differently. The major difference is that two transitions are observed for the pristine material, whereas only one appears for the PEB-MWCNT composites. Temperature sweeps of the samples have shown that the transitions are independent of temperature. The transitions are clearly a property of the filler, and are related to the accumulation and release of charge carriers at the interface between the filler and the polymer matrix as described by Logakis et al. (34) for a polyamide/MWCNT composite. Through functionalization of the MWCNT the interaction between the nanotube and the matrix is improved, which results in a more homogeneous interface and only one polarization of the interface. We have observed similar tendencies for other composite systems, with poor dispersion of the MWCNT filler. In such systems there are both agglomerated and dispersed fillers, which give rise to this difference in polarization. The performance of the composites at higher temperatures was investigated through DRS, where the results from the $1 \mathrm{wt} \%$ composites are shown in Figure 5.

Figure $5 \mathrm{a}$ and $\mathrm{b}$

The composite with the functionalized filler shows a constant resistance throughout the investigated range, which contrasts with the pristine material. This illustrates the substantial impact that a low degree of modification of the MWCNT has on the properties of the composite. In addition to this, the decrease in resistance with an increase in temperature shows that the composites do have a negative temperature coefficient of resistance, which is typical for semiconducting materials. Similar plots of the imaginary part of the complex impedance ( $Z_{s}{ }_{s}^{\prime \prime}$, Figures 5 and 6 in the supporting information) allows us to determine the activation energies of the process and these are summarized in Table 2.

Table 2

The activation energies and relaxation data shows that the composite containing $1 \mathrm{wt} \%$ PEB-MWCNT with the lowest activation energy $\left(\Delta \mathrm{E}_{\tau}\right)$ and shortest relaxation time $\left(\tau_{0}\right)$ is superior to the others.

\section{Conclusion}

A novel azide functional compatibilizer based on $\alpha$-azido-poly(ethylene-co-butylene) has been prepared and applied in functionalization of an industrial grade MWCNT. The grafting procedure was found to be a highly efficient method for obtaining the desired loading of polymer on the MWCNT with a minimal loss of reagent. Composites prepared with PEB-MWCNT exhibited good dispersion and percolation thresholds below $0.3 \mathrm{wt} \%$ ( 0.15 vol\%). Moreover the novel filler has been found to result in superior electronic properties of the composite, where especially the $1 \mathrm{wt} \%$ composite resulted in higher conductivity and improved thermal stability compared to the corresponding pristine material. These results illustrate that 
with the proper use of a good compatibilizer improved conductive properties can be obtained for functionalized fillers in PP composites.

\section{Acknowledgements}

The authors would like to thank Lars Schulte for SEM investigations. The Innovation Consortium "Extreme Materials for Extreme Environments" funded by the Danish Agency for Science Technology and Innovation under contract 08-034101 as well as the EU programme "Nanotough" is acknowledged for financial support. Finally, Kuraray Co.Ltd. is thanked for kindly donating a sample of their Kraton L-1203.

\section{References}

1. Paul DR, and Robeson LM. Polymer nanotechnology: Nanocomposites:Polymer 2008;49:3187-3204.

2. Spitalsky Z, Tasis D, Papagelis K, and Galiotis C. Carbon nanotube-polymer composites: Chemistry, processing, mechanical and electrical properties:Progress in Polymer Science 2010;35:357-401

3. Hu L, Hecht DS, and Grüner G. Carbon nanotube thin films: fabrication, properties, and applications.Chemical Reviews 2010;110:5790-844.

4. Schnorr JM, and Swager TM. Emerging Applications of Carbon Nanotubes:Chemistry of Materials 2011;23:646-657.

5. Watson K, Ghose S, Delozier D, Smithjr J, and Connell J. Transparent, flexible, conductive carbon nanotube coatings for electrostatic charge mitigation:Polymer 2005;46:2076-2085.

6. Al-Saleh $\mathrm{MH}$, and Sundararaj U. Electromagnetic interference shielding mechanisms of CNT/polymer composites:Carbon 2009;47:1738-1746.

7. Saini P, Choudhary V, Singh B, Mathur R, and Dhawan S. Polyaniline-MWCNT nanocomposites for microwave absorption and EMI shielding:Materials Chemistry and Physics 2009;113:919-926.

8. Liao S-H, Weng C-C, Yen C-Y, Hsiao M-C, Ma C-CM, Tsai M-C, Su A, Yen M-Y, Lin YF, and Liu P-L. Preparation and properties of functionalized multiwalled carbon nanotubes/polypropylene nanocomposite bipolar plates for polymer electrolyte membrane fuel cells:Journal of Power Sources 2010;195:263-270.

9. Grossiord N, Loos J, Regev O, and Koning CE. Toolbox for Dispersing Carbon Nanotubes into Polymers To Get Conductive Nanocomposites:Chemistry of Materials 2006;18:10891099.

10. Tasis D, Tagmatarchis N, Bianco A, and Prato M. Chemistry of carbon nanotubes. Chemical Reviews 2006;106:1105-36. 
11. Yang B-X, Shi J-H, Pramoda KP, and Goh SH. Enhancement of the mechanical properties of polypropylene using polypropylene-grafted multiwalled carbon nanotubes:Composites Science and Technology 2008;68:2490-2497.

12. Blake R, Gun'ko YK, Coleman J, Cadek M, Fonseca A, Nagy JB, and Blau WJ. A generic organometallic approach toward ultra-strong carbon nanotube polymer composites.Journal of the American Chemical Society 2004;126:10226-7.

13. Bahr JL, and Tour JM. Covalent chemistry of single-wall carbon nanotubes:Journal of Materials Chemistry 2002;12:1952-1958.

14. Fragneaud B, Masenelli-Varlot K, González-Montiel A, Terrones M, and Cavaillé J-Y. Electrical behavior of polymer grafted nanotubes/polymer nanocomposites using N-doped carbon nanotubes:Chemical Physics Letters 2007;444:1-8.

15. Lee S, Cho E, Jeon S, and Youn J. Rheological and electrical properties of polypropylene composites containing functionalized multi-walled carbon nanotubes and compatibilizers:Carbon 2007;45:2810-2822.

16. Singh P, Campidelli S, Giordani S, Bonifazi D, Bianco A, and Prato M. Organic functionalisation and characterisation of single-walled carbon nanotubes.Chemical Society Reviews 2009;38:2214-30.

17. Homenick CM, Lawson G, and Adronov A. Polymer grafting of carbon nanotubes using living free-radical polymerization:Polymer Reviews 2007;47:265-290.

18. Liu Y-L, and Chen W-H. Modification of Multiwall Carbon Nanotubes with Initiators and Macroinitiators of Atom Transfer Radical Polymerization:Macromolecules 2007;40:88818886.

19. Wu H, Tong R, Qiu X, Yang H, Lin Y, Cai R, and Qian S. Functionalization of multiwalled carbon nanotubes with polystyrene under atom transfer radical polymerization conditions:Carbon 2007;45:152-159.

20. Liu Y-L, Chen W-H, and Chang Y-H. Preparation and properties of chitosan/carbon nanotube nanocomposites using poly(styrene sulfonic acid)-modified CNTs:Carbohydrate Polymers 2009;76:232-238.

21. Daugaard AE, Jankova K, Bøgelund J, Nielsen JK, and Hvilsted S. Novel UV initiator for functionalization of multiwalled carbon nanotubes by atom transfer radical polymerization applied on two different grades of nanotubes:Journal of Polymer Science Part A: Polymer Chemistry 2010;48:4594-4601.

22. Holzinger M, Vostrowsky O, Hirsch A, Hennrich F, Kappes M, Weiss R, and Jellen F. Sidewall Functionalization of Carbon Nanotubes:Angewandte Chemie International Edition 2001;40:4002-4005. 
23. Qin S, Qin D, Ford WT, Resasco DE, and Herrera JE. Functionalization of Single-Walled Carbon Nanotubes with Polystyrene via Grafting to and Grafting from Methods:Macromolecules 2004;37:752-757.

24. McIntosh D, Khabashesku VN, and Barrera EV. Benzoyl Peroxide Initiated In Situ Functionalization, Processing, and Mechanical Properties of Single-Walled Carbon Nanotube-Polypropylene Composite Fibers:Journal of Physical Chemistry C 2007;111:15921600 .

25. Zheng J, Zhu Z, Qi J, Zhou Z, Li P, and Peng M. Preparation of isotactic polypropylenegrafted multiwalled carbon nanotubes (iPP-g-MWNTs) by macroradical addition in solution and the properties of iPP-g-MWNTs/iPP composites:Journal of Materials Science 2010;46:648-658.

26. Wepasnick KA, Smith BA, Bitter JL, and Fairbrother HD. Chemical and structural characterization of carbon nanotube surfaces. Analytical and bioanalytical chemistry 2010;396:1003-14.

27. Grady BP. Recent Developments Concerning the Dispersion of Carbon Nanotubes in Polymers:Macromolecular Rapid Communications 2010;31:247-257.

28. Logakis E, Pollatos E, Pandis C, Peoglos V, Zuburtikudis I, Delides CG, Vatalis a., Gjoka M, Syskakis E, and Viras K. Structure-property relationships in isotactic polypropylene/multiwalled carbon nanotubes nanocomposites:Composites Science and Technology 2010;70:328335.

29. Lillehei PT, Kim J-W, Gibbons LJ, and Park C. A quantitative assessment of carbon nanotube dispersion in polymer matrices.Nanotechnology 2009;20:325708.

30. Pötschke P, Fornes T, and Paul D. Rheological behavior of multiwalled carbon nanotube/polycarbonate composites:Polymer 2002;43:3247-3255.

31. Zhang Q, Fang F, Zhao X, Li Y, Zhu M, and Chen D. Use of dynamic rheological behavior to estimate the dispersion of carbon nanotubes in carbon nanotube/polymer composites. The journal of physical chemistry. B 2008;112:12606-11.

32. Tchmutin I, Ponomarenko A, Krinichnaya E, Kozub G, and Efimov O. Electrical properties of composites based on conjugated polymers and conductive fillers:Carbon 2003;41:13911395.

33. Tjong S, Liang G, and Bao S. Electrical behavior of polypropylene/multiwalled carbon nanotube nanocomposites with low percolation threshold:Scripta Materialia 2007;57:461464.

34. Logakis E, Pandis C, Peoglos V, Pissis P, Pionteck J, Pötschke P, Mičušík M, and Omastová $\mathrm{M}$. Electrical/dielectric properties and conduction mechanism in melt processed polyamide/multi-walled carbon nanotubes composites:Polymer 2009;50:5103-5111. 


\section{Figure captions:}

Scheme 1: Preparation of the poly(ethylene-co-butylene) functionalized MWCNT by nitrene addition

Figure 1: TGA (a) and Raman spectroscopy (b) of the PEB functionalized MWCNT compared to the pristine MWCNT.

Figure 2: Scanning electron micrographs of composites containing pristine MWCNT are shown in the first row, whereas composites with PEB-MWCNT are shown in the second row. The micrographs have been acquired at high voltage (5kV) allowing charge accumulation. Charged areas on the surface (bright areas) signify areas without contact to the percolated network and correspondingly dark regions illustrate access to the percolated network.

Figure 3: The real part of the complex conductivity $\left(\sigma^{\prime}\right)$ as a function of frequency. A: Pristine MWCNT composites; B: PEBMWCNT composites.

Figure 4: Real $\left(\varepsilon^{\prime}\right)$ and imaginary $\left(\varepsilon^{\prime \prime}\right)$ part of the complex permittivity for pristine-MWCNT $(A)$ and PEB-MWCNT (B) composites with varied filler concentration.

Figure 5: Real part of the complex impedance $\left(Z_{s}^{\prime}\right)$ measured as a function of temperature from $25^{\circ} \mathrm{C}$ (blue) to $135^{\circ} \mathrm{C}$ (red). A: 1wt\% pristine MWCNT composite in PP, B: 1wt\% PEB-MWCNT composite in PP.

\section{Tables:}

Table 1: Composite content of modified and pristine MWCNT correlated to the respective conductivities at $1 \mathrm{~Hz}$.

Table 2: Relaxation strength of the composites derived from the loss part of the complex impedance. ${ }^{a}$ 
Table 1: Composite content of modified and pristine MWCNT correlated to the respective conductivities at $1 \mathrm{~Hz}$.

\begin{tabular}{ccccccc}
\hline \multirow{2}{*}{ Composites } & \multicolumn{2}{c}{ MWCNT content } & \multicolumn{2}{c}{ Conductivity $(\mathbf{S} / \mathbf{c m})$} & \multicolumn{2}{c}{ Critical frequency $\left(\mathbf{f}_{\mathrm{c}}(\mathbf{H z})\right)$} \\
\cline { 2 - 7 } & wt\% & vol\% & Prist MWCNT & PEB-MWCNT & Prist MWCNT & PEB-MWCNT \\
\hline B & 1,00 & 0,52 & $1,13^{*} 10^{-7}$ & $2,44 * 10^{-6}$ & 1670 & 94900 \\
C & 0,60 & 0,31 & $4,96 * 10^{-8}$ & $1,63 * 10^{-8}$ & 1670 & 2150 \\
D & 0,30 & 0,15 & $2,16^{*} 10^{-9}$ & $1,87 * 10^{-9}$ & 1670 & 200 \\
E & 0,10 & 0,05 & $1.78 * 10^{-15}$ & $7.60 * 10^{-15}$ & -- & --
\end{tabular}


Table 2: Relaxation strength of the composites derived from the loss part of the complex impedance. ${ }^{a}$

\begin{tabular}{ccc}
\hline Samples & $\Delta \mathrm{E}_{\tau}(\mathrm{Ev})$ & $\tau_{0}(\mathbf{s})$ \\
\hline PEB-MWCNT 1wt\% & 0.26 & $1.04 * 10^{-9}$ \\
PEB-MWCNT 0.66wt\% & 0.43 & $1.79 * 10^{-10}$ \\
PEB-MWCNT 0.33wt\% & 0.45 & $1.8 * 10^{-9}$ \\
Prist-MWCNT 1 wt\% & 0.35 & $1.65 * 10^{-9}$ \\
Prist-MWCNT 0.66 wt\% & 0.32 & $4.85 * 10^{-9}$ \\
Prist-MWCNT 0.33 wt\% & 0.43 & $2.1 * 10^{-9}$
\end{tabular}

a) Only percolated samples can be examined, thus only samples containing $0.3 \mathrm{wt} \%$ and above have been applied. 


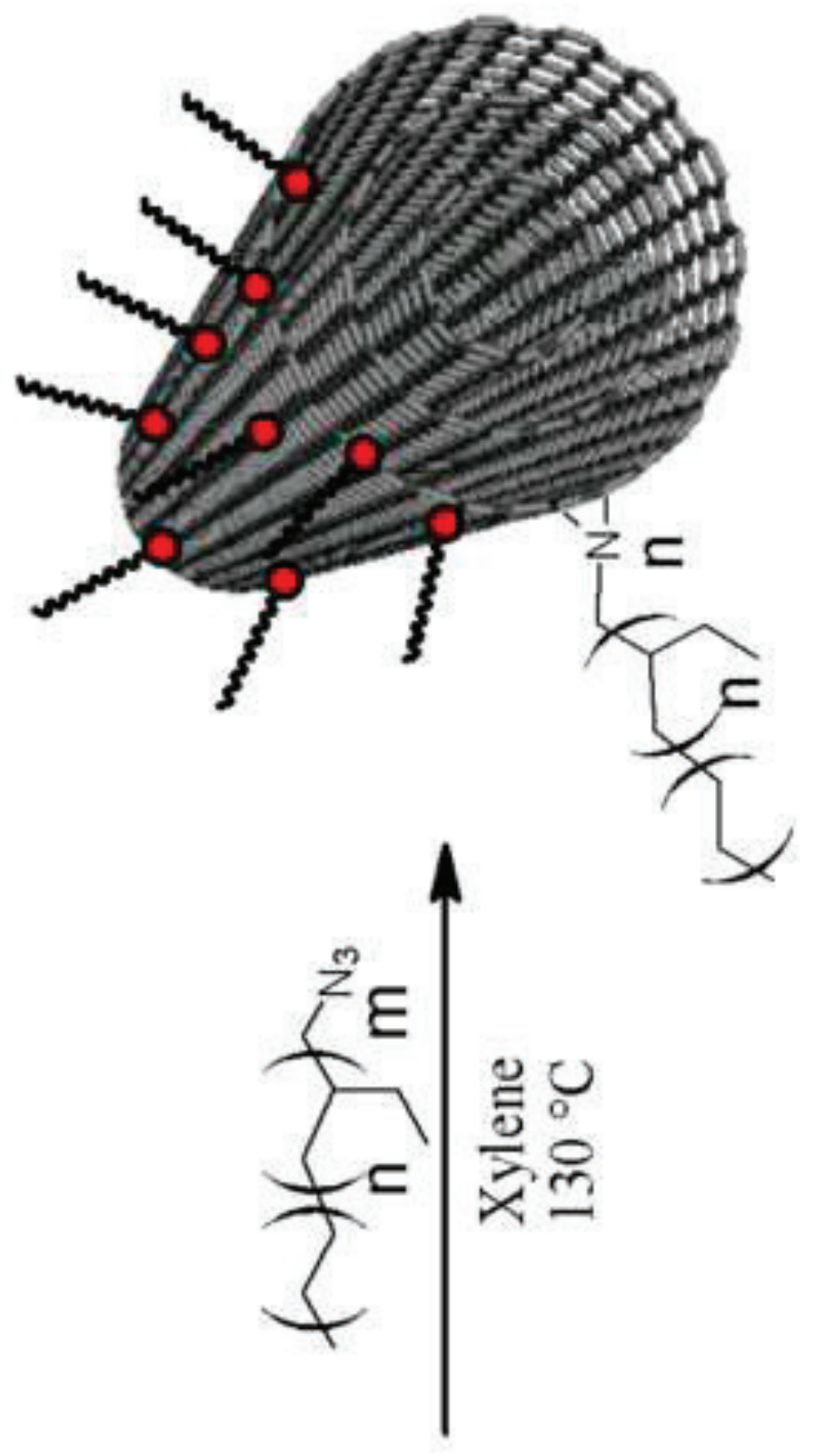

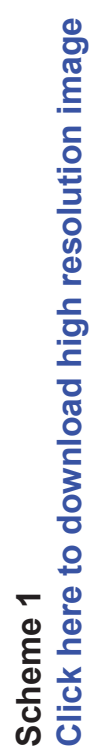

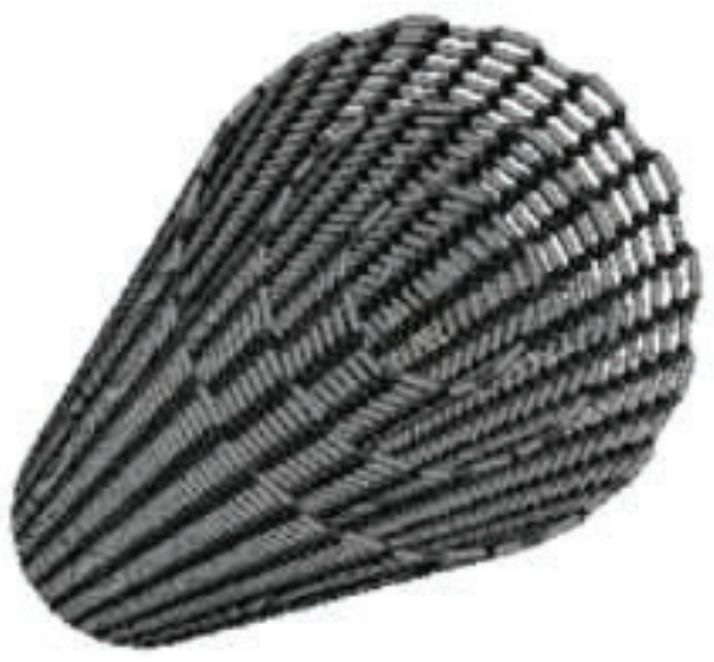


A

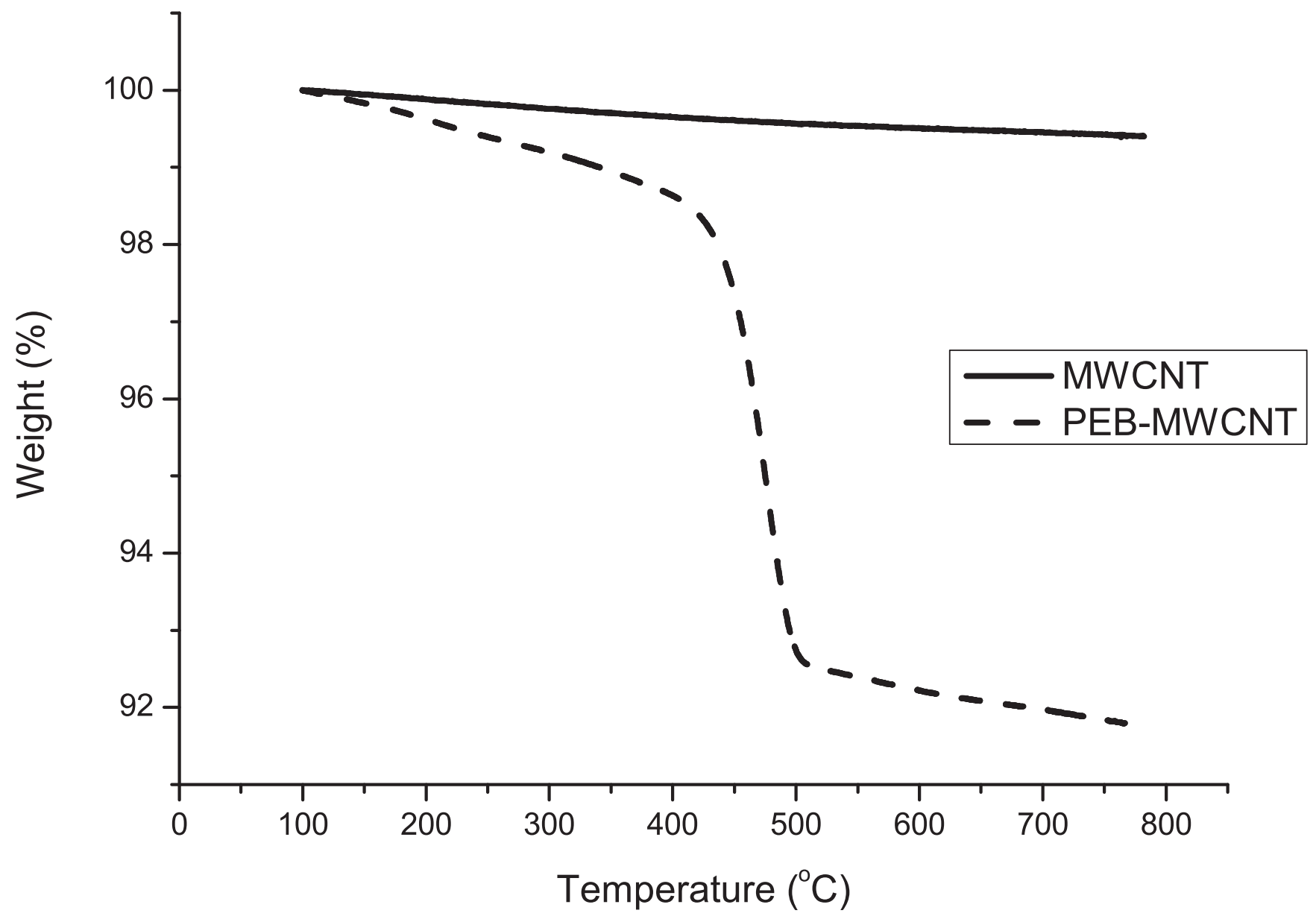




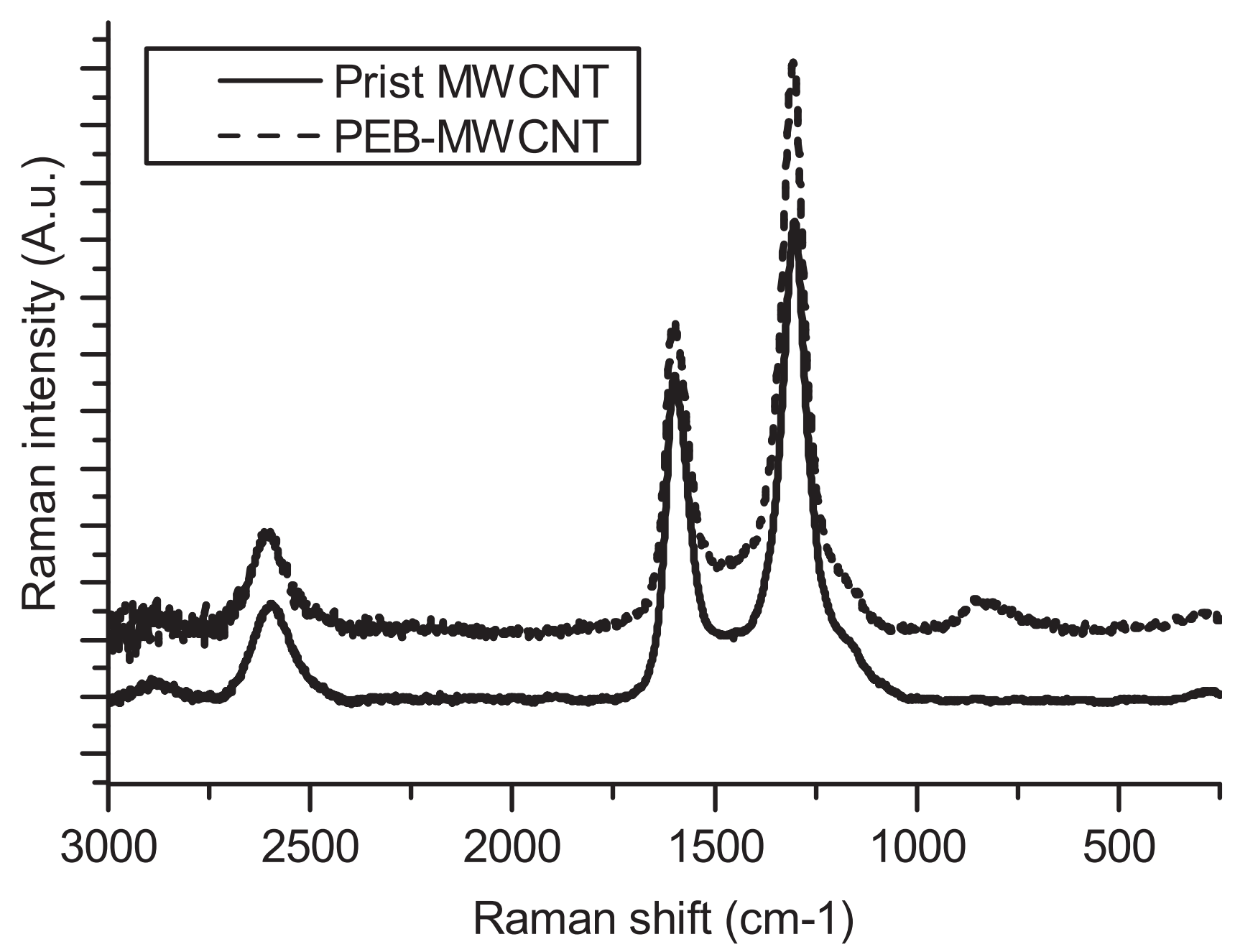

B 


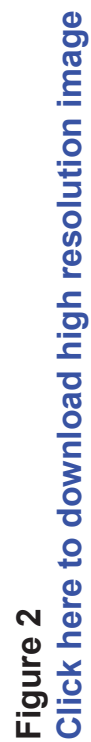

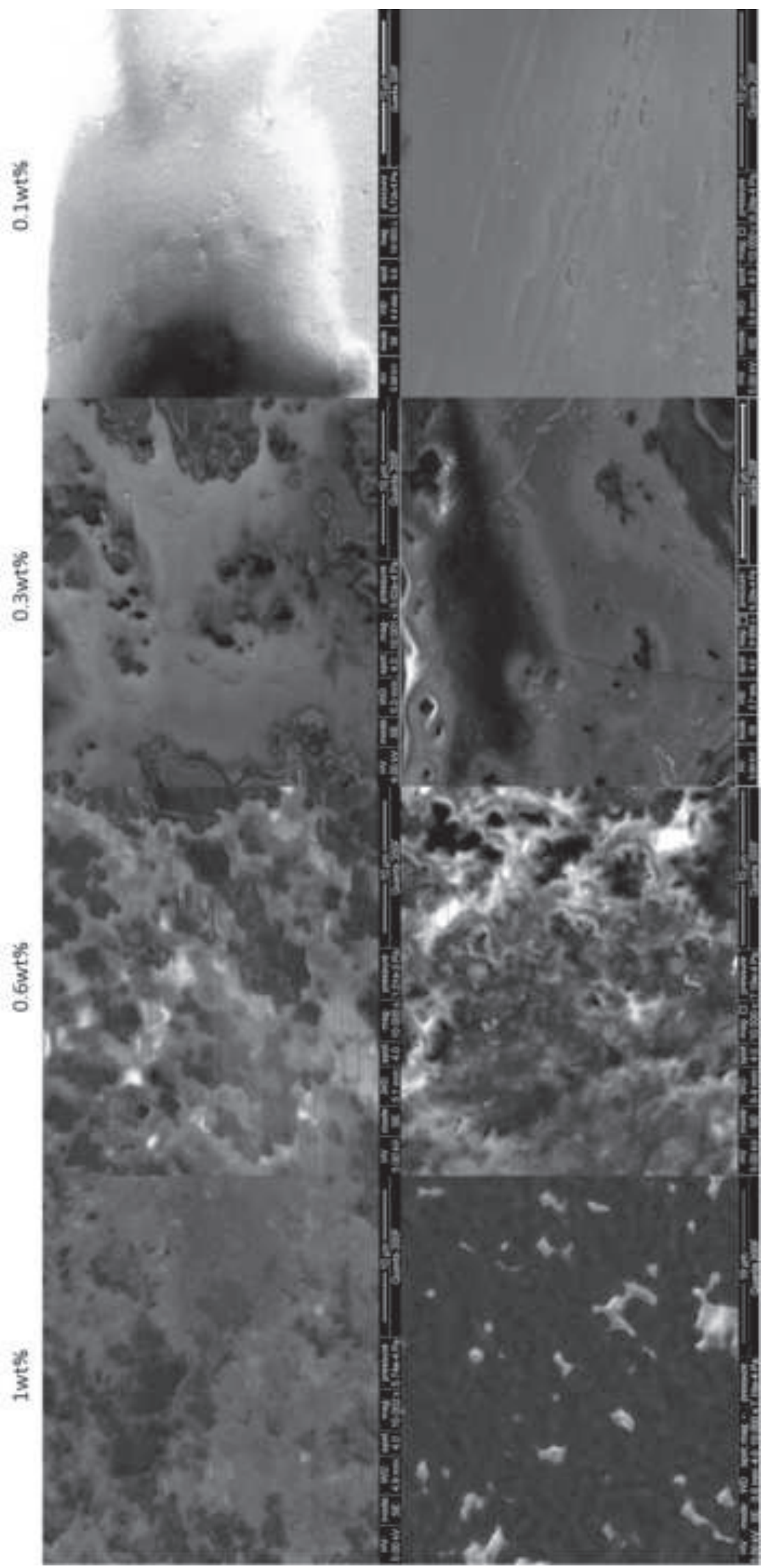


A

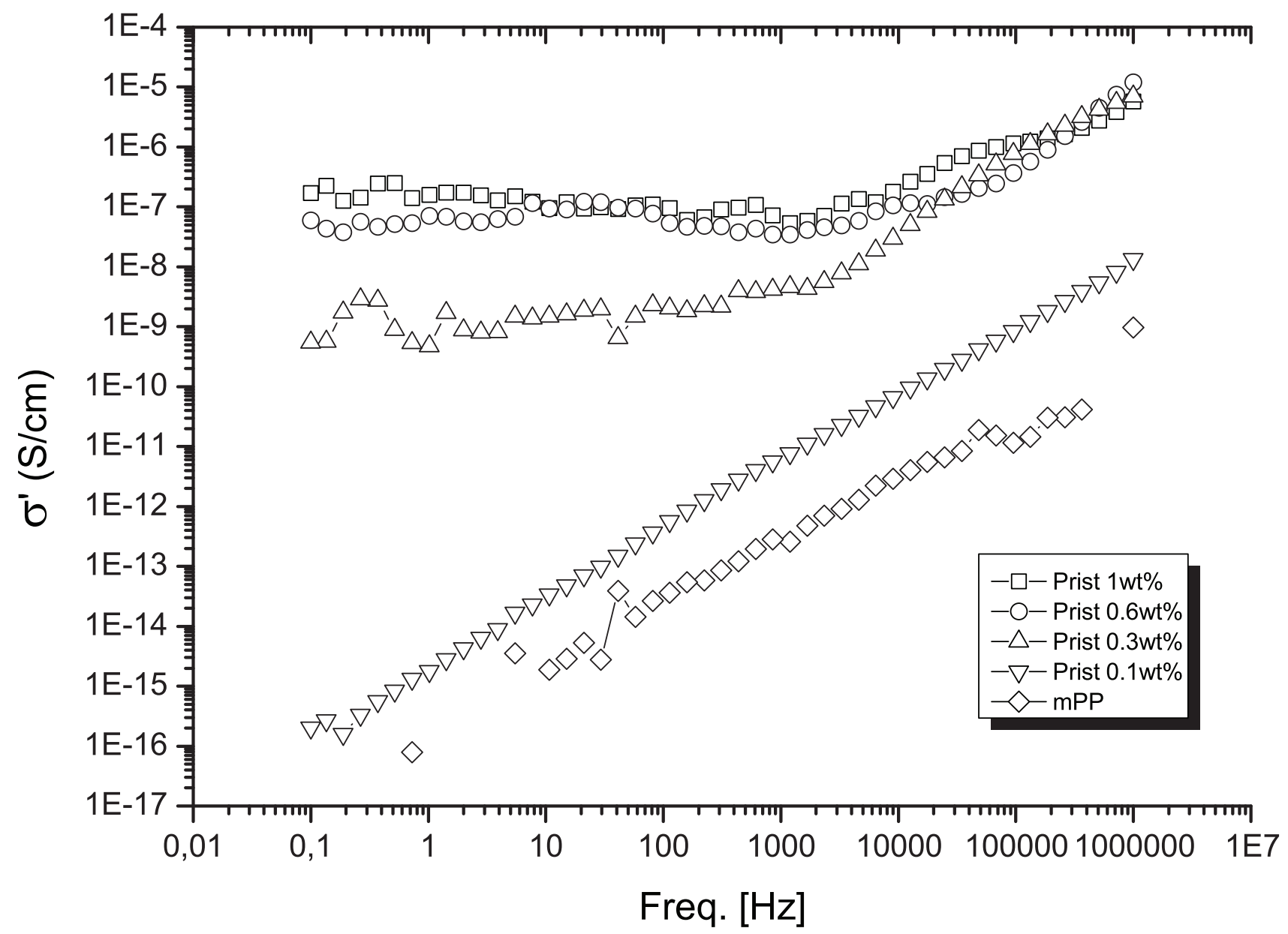




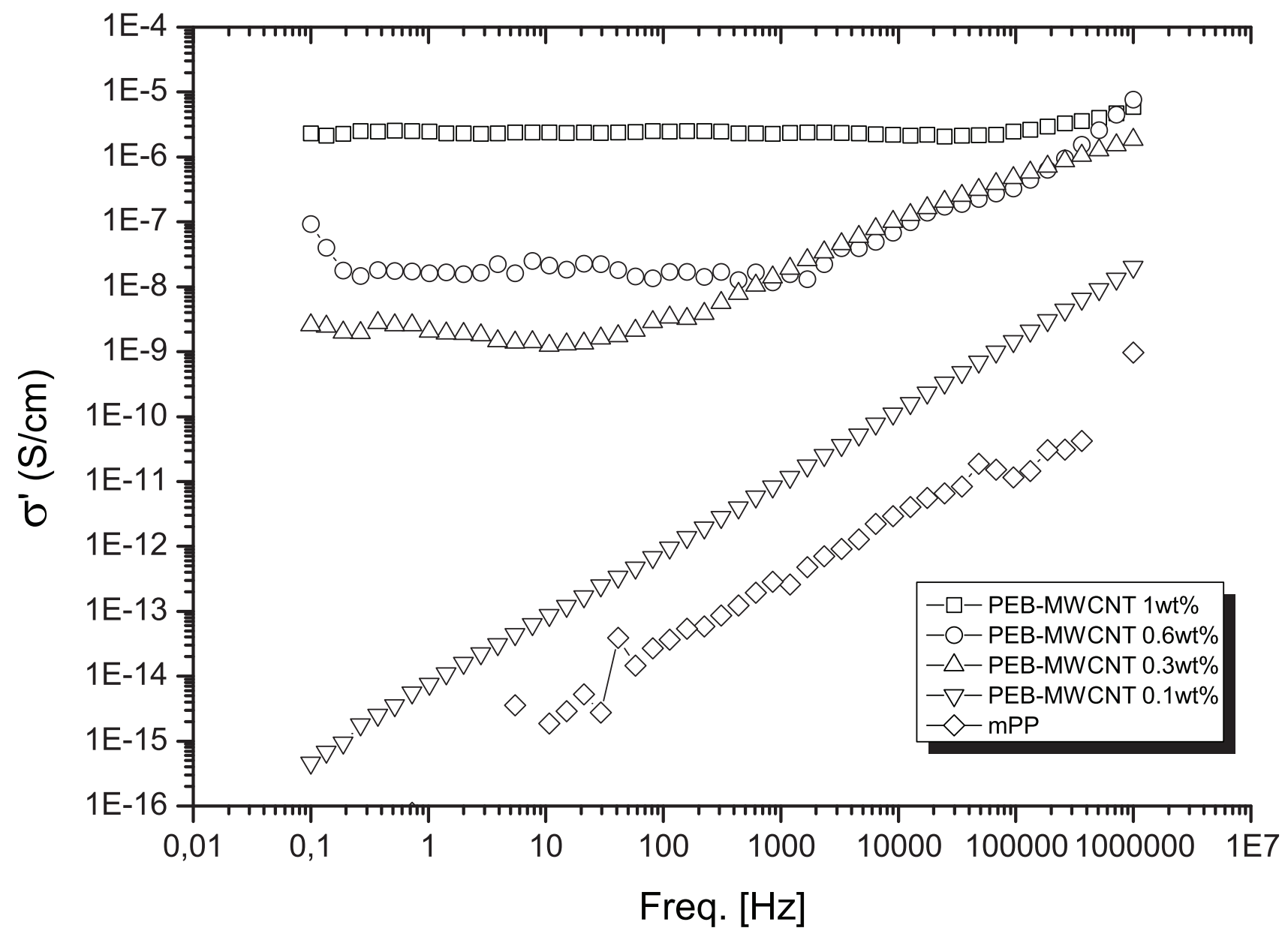


A

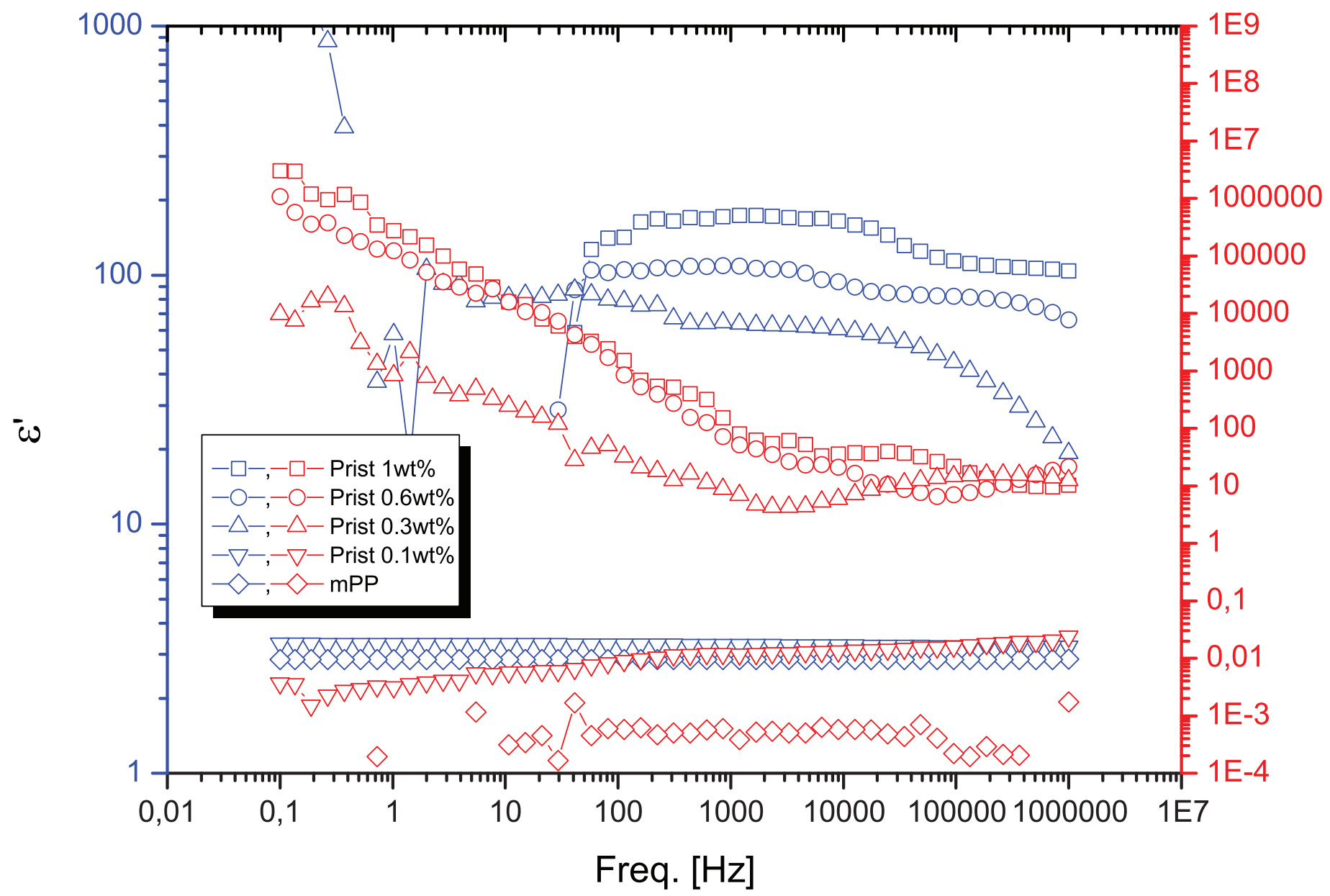

$\bar{\omega}$ 


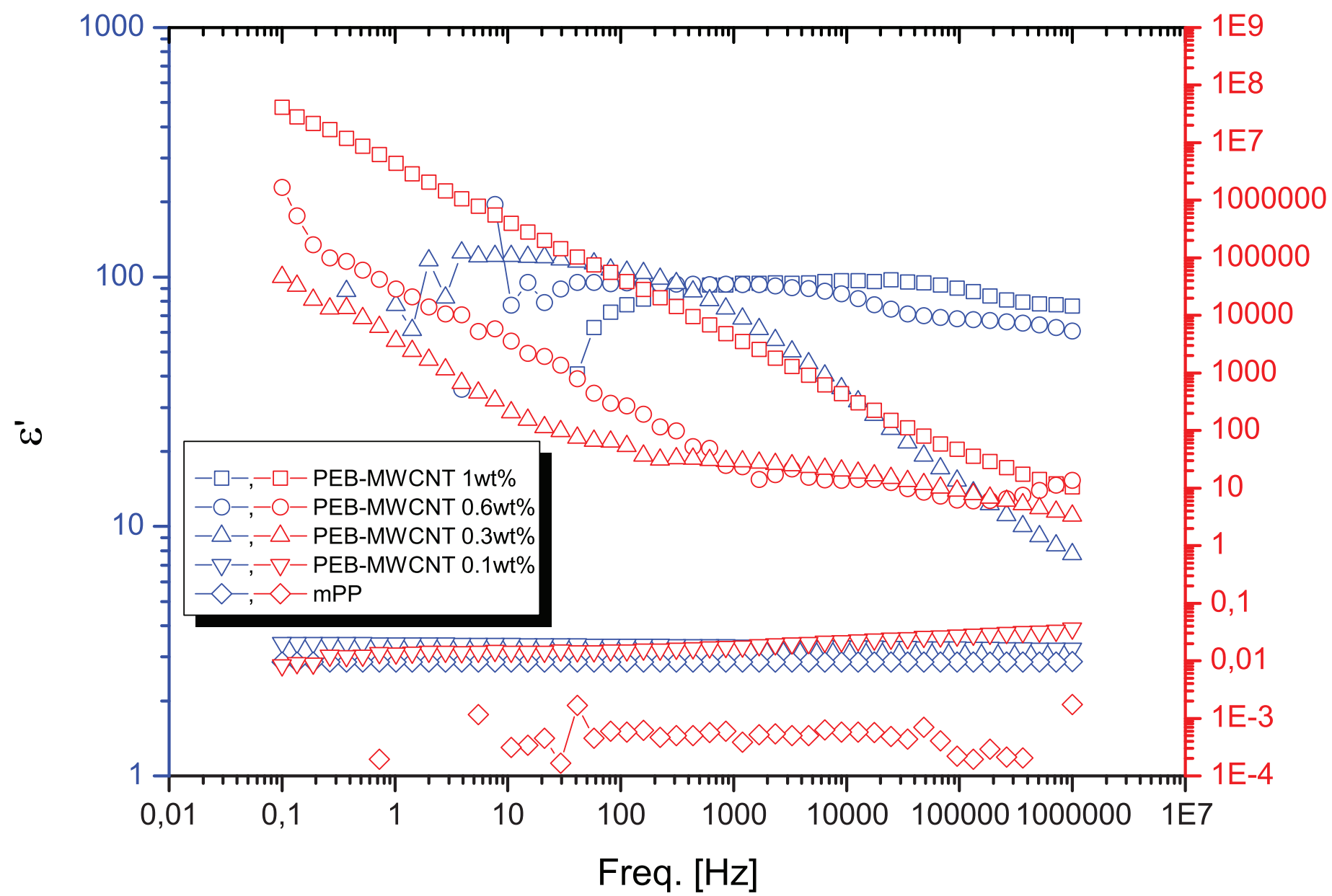

$\omega$ 
A

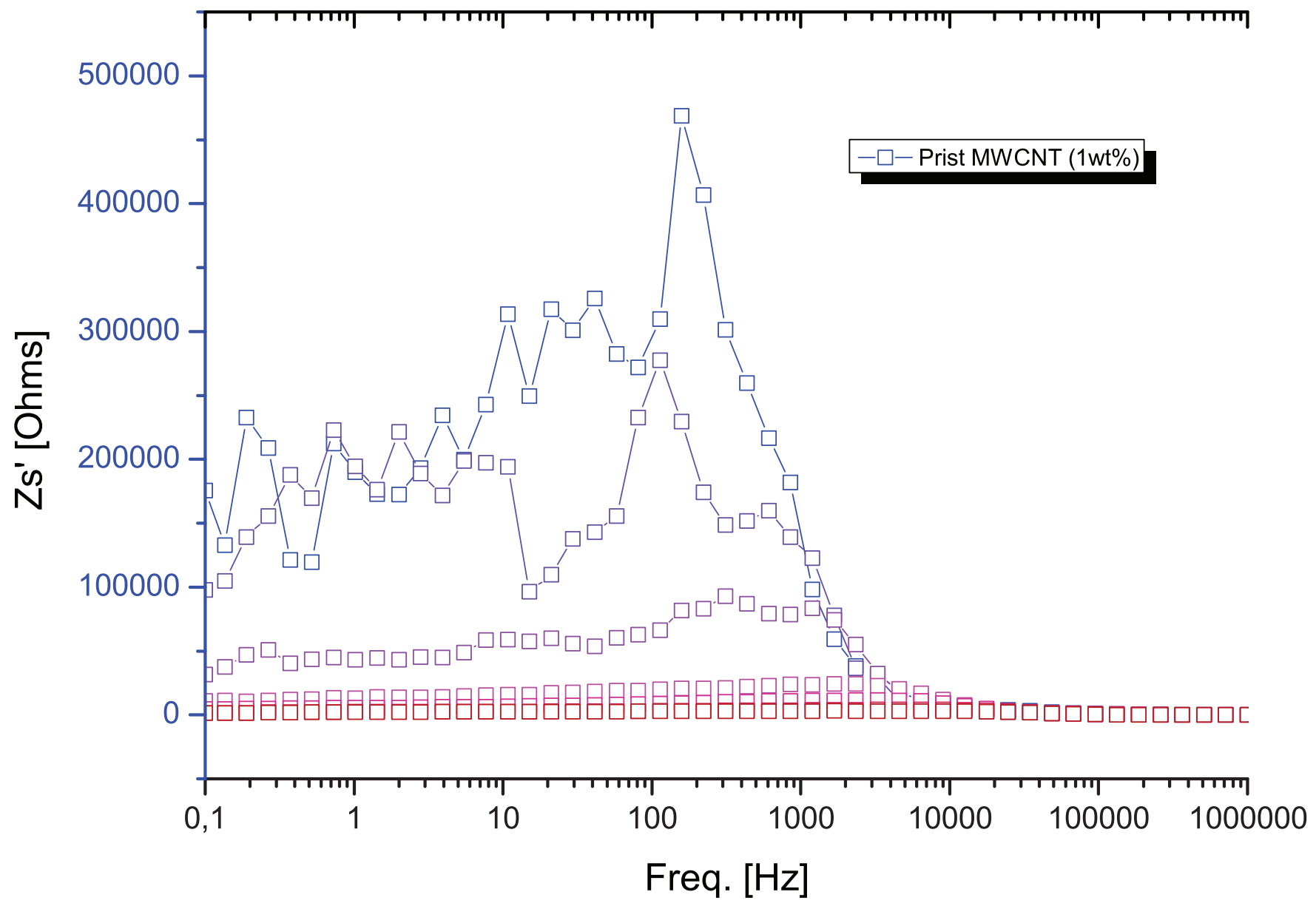


B

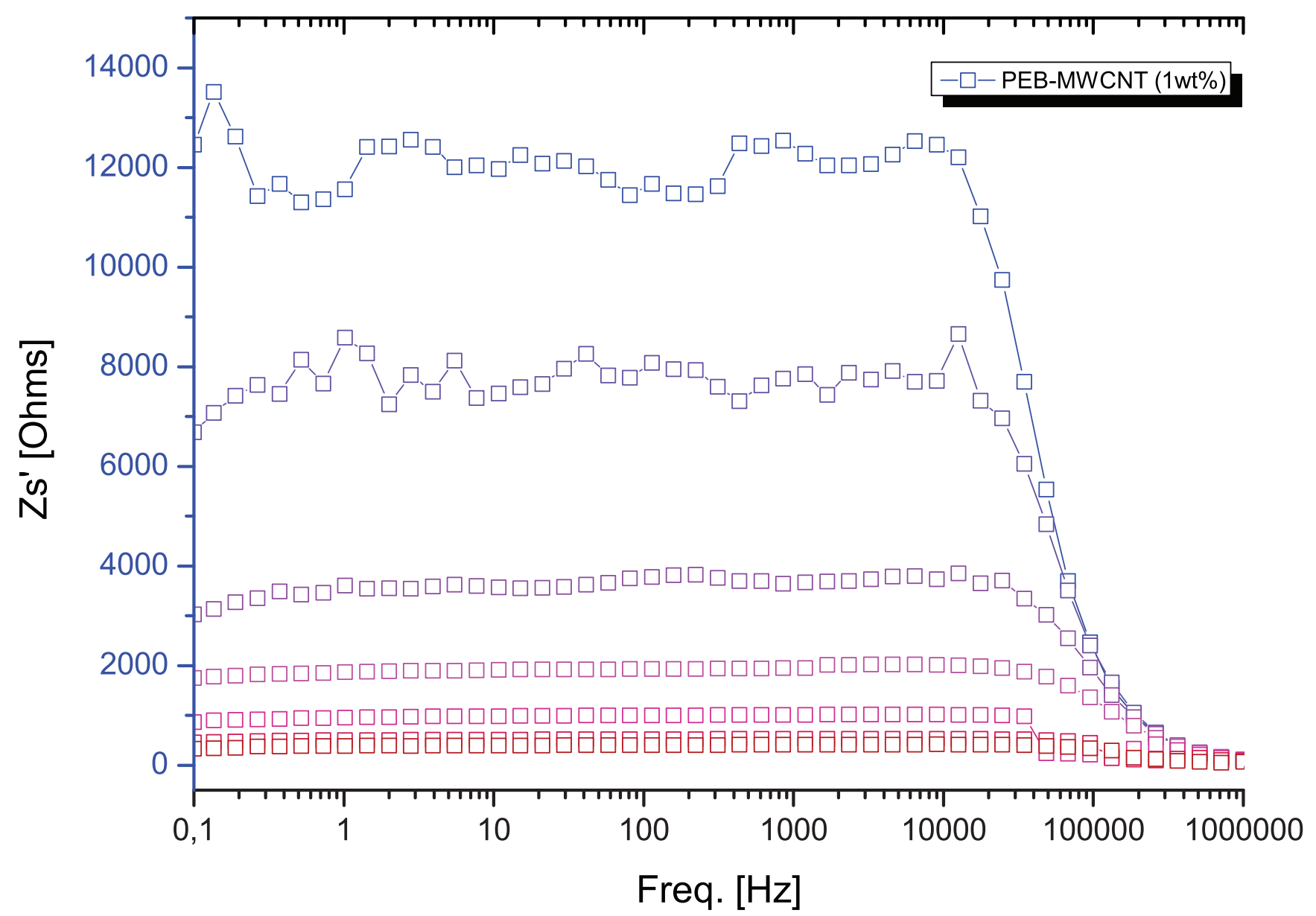


Click here to download Supplementary Material: Supporting information - 26-01-12.docx 